In countries without a comprehensive national health service, many patients with rheumatic diseases cannot afford the cost of expensive $x$ rays and diagnostic tests. Physicians practising rheumatology in these countries must accordingly sharpen up their clinical skills. The book by Rotés-Querol and his colleagues sets out in great detail (and with much emphasis on the underlying and surface anatomy) the methods of examination of the spine and joints and the detection of the clinical signs of the various rheumatic diseases. It opens with a detailed chapter on the physiology of pain and areas of pain referral. Then follows a chapter on the signs of articular inflammation, on deformity, on the noises arising in joints, and on limitation of movement and hypermobility.
The third, fourth, and fifth chapters deal with the clinical manifestations of rheumatic diseases in extra-articular structures, in the bones, and in the nervous system. Chapter 6, by G. Tiñol Aguade, deals in considerable detail with the skin manifestations of locomotor diseases and has many illustrations, most of them in colour. The second half of the book is devoted to the examination of the individual joints and is again very clearly illustrated. The chapter on examination of the spine deserves special mention. A small final section is devoted to single-page summaries of the main rheumatic diseases. The book is notable for its clarity and scope. It is beautifully bound and the many references cited are accurately listed.

A. St. J. Dixon.

\title{
OBITUARY PHILIP HENCH, 1896-1965
}

Philip Hench died suddenly while on holiday, on March 31. He was Professor Emeritus of Medicine in the University of Minnesota and head of the Section of Rheumatic Diseases at the Mayo Clinic.

In 1950 he became Nobel Laureate for physiology and medicine "for discoveries in the hormones of the adrenal cortex, their structure, and biological effects", which were the result of twenty years of painstaking search, in association with his colleague E. C. Kendall, for the hypothetical rheumatic "substance X". It was this, they postulated, which must control the remissions in rheumatoid arthritis which they had observed to occur during pregnancy, jaundice, and one or two other conditions. The culmination of their researches was the memorable dramatic demonstration of the clinical effects of cortisone and ACTH which Hench gave at the seventh meeting of the International League against Rheumatism during its session in New York in September, 1949.

The news of this "wonder drug" rapidly became front-page news all over the world. Hench and Kendall, however, were careful to point out that their trials should at that stage still be considered to be in the nature of physiological experiments, and not as a cure for rheumatoid arthritis and other diseases. Nonetheless their warning went unheeded, and a period of disillusion resulted, to Hench's great distress.

When they were awarded the Nobel Prize in 1950 Hench with his customary generosity distributed part of it among his co-workers. Countless academic and other honours followed from all parts of the world. The United States Government entrusted him with a leading part in establishing the new Department of Arthritis and Metabolism in the National Institutes of Health in Washington which the late Dr. Joe Bunim came to direct; and in 1962 he and his wife were bidden to dine at the White
House with President John F. Kennedy. Hench was a founder and President of the Arthritis and Rheumatism Association, and in 1948 was awarded the Heberden Medal and later honorary membership of the Heberden Society. For many years he acted as an American Associate Editor of the Annals of Rheumatic Diseases and rendered great service; while the "Annual Rheumatism Reviews" of which he was the originator and chief editor constituted one of the formative influences of the new discipline of rheumatology, of which he can be considered a founding member.

Many of the present leaders of American rheumatology gained their first enthusiasm for the subject while serving under him during the war in the U.S. Army's great Rheumatic Centre of which he was the director, with the rank of Colonel. He was a brilliant and forceful speaker in spite of the misfortune of a cleft palate, and was a welcome figure at meetings all over the world. Wherever he went he left a host of devoted friends with whom he would keep in touch by correspondence-always in his own hand. He will be sorely missed by the older generation in this country and elsewhere.

The interest of his visits to England was not confined to rheumatology and medicine, for in addition to a love of tennis, music, and photography, coupled with considerable executive skill in each, he was fascinated by the Sherlock Holmes saga. He spent much time with fellow enthusiasts of the "Baker Street Irregulars Society", and wrote on the subject. He was also a considerable expert on certain aspects of medical history, and at the time of his death was engaged on a monumental work on Walter Reed and the discovery of the causes of yellow fever.

In 1927 Hench married Mary Kahler, his devoted companion throughout life. They had two daughters and two sons. One of his sons has followed his father into rheumatology.

W. S. C. Copeman. 